ity. The rhetorical question, Must God Create the Best?, is the title of the first paper and explores the Judaeo-Christian ethic that allows a less than perfect world to give room for God's grace to act.

Another paper in this section, entitled Parenting, Bonding and Valuing the Retarded, is of particular relevance for those who work with neonates. A sentence out of this chapter is a good example of the pithy language used in much of this book: 'Professionals cannot ... treat the child simply as a checked piece of luggage - containing so many grammes of bodyweight, lab values and deficits - and expect the child to come home and be embraced'.

I thoroughly recommend this book to those who want to delve deeper into the ethical issues relevant for mentally handicapped people and in particular to those who are willing to look at themselves, their own attitudes and expectations, and from where their motivation comes.

PROFESSOR JOAN BICKNELL Professor of the Psychiatry of Mental Handicap,

St George's Hospital Medical School London SW17

\section{Birth Reborn - What Birth Can and Should Be}

Michel Odent, 123 pages, London, £9.95, Souvenir Press, 1984

This book raises for me two ethical issues, one of which causes me no problems, whilst the other one does.

Michel Odent sets out in this book the attitudes that he has developed since 1962 , and describes the system that he is still developing in caring for childbearing women in the French provincial town of Pithiviers. In a nutshell, he believes that women should be in control of what happens to them when their babies are born and that medical intervention should be kept to a minimum. In respecting the dignity and feelings of individual women in labour he shows that the results can be as good, if not better, in terms of safety for both mother and child, to say nothing about emotional satisfaction, than birth by high technology. Almost everything that Odent says I can endorse without reservation. His beautifully illustrated account is convincing. It certainly will be to prospective parents, if not to sceptical midwives and obstetricians.

I have practically no difficulty in agreeing with everything that he says and does. I believe that he raises an ethical issue in challenging the established views of conventional obstetric practice, certainly in this country and in most others. I believe that Odent is morally right to propagate his views, because he can support them with observed and recorded facts.

But the second ethical issue leaves me with an unresolved conflict. The issue is whether or not it is right to create expectations for people bearing children that are dependent on one personality for their fulfillment, so much so that he becomes a 'cult' figure. The 'pilgrimage to Pithiviers' is a reality for many women either in fact or metaphorically. Such women believe, and a few even to the point of obsession, that only in Pithiviers can perfection in childbirth be achieved. I am sure that this is and was not intended by Michel Odent, nevertheless it has happened. I feel sure that Odent wishes women to be selfreliant both emotionally and physically during birth. I am also sure that he is right to wish this. But, I am sorry that in spite of what he may wish a cult has been created, because perfection in childbirth is not usually attainable, and because it cannot be right that only a minority of women are able to join the cult. However, I believe that it is necessary for professionals like Odent to polarise opinion, not only in order to change the attitudes of other professionals, but also to provide insight and strength for women themselves. My question remains, how do we change the attitudes of professionals towards childbearing women without creating dependence on the personality preparing the way for change?

PETER HUNTINGFORD Consultant Obstetrician, Maidstone Health District

\section{Current Opinions of the Judicial Council of the American Medical Association}

Prepared by the Judicial Council of the AMA, 47 pages, Chicago, $\$ 5$

paperback, 1984;

\section{The Handbook of Medical Ethics, 3rd edition}

British Medical Association, 111 pages, $£ 5$ to non-members, £2 to BMA members, London, 1984

These short texts cover a wide range of ethical problems relating to the professional responsibilities and obligations of physicians. The AMA text is the shorter of the two since it is not explicitly concerned with behaviour relating to broader moral issues. In contrast the BMA's Handbook offers a more thorough survey of the whole gamut of ethical issues.

At first sight there is little distinction between the two texts. Both begin with a short history of medical ethics, referring to the Code of Hammarabi, the Oath of Hippocrates, and Thomas Percival's Code of Medical Ethics of 1803. The differences which eventually emerge reflect the respective economic climates in which medicine is practised in the United Kingdom and the USA. There is, for example, much more attention to ethical problems arising out of fee-paying practices in the AMA Opinions which cover interest charges on fees, fee splitting, laboratory bills, and fees for surgical assistance. In this respect the AMA Opinions reflect a more contractual relationship between doctor and patient than the BMA guidelines. However, both deal in a similar way with certain crucial issues such as genetic engineering, termination of pregnancy, in vitro fertilisation, confidentiality, use of computers, organ transplants, and the participation of physicians in capital punishment which is ruled to be contrary to the profession's ethics - the BMA extends this prohibition to the attendance at corporal punishment and the interrogation of prisoners.

Since it is the more comprehensive survey the BMA Handbook covers issues governing the relationship between doctors and individuals and between doctors and other groups in society. Like its American counterpart it surveys the relationship between professional discipline and the law. Of particular relevance are the ten pages dealing with ethical dilemmas which highlight areas where a broad consensus of opinion has been reached and where it has not. It might be objected that the discussion of ethical dilemmas is $\omega$ restricted. In the light of the vast output of literature on terminal illness and death, where crucial discussions turn on the interpretation of expressions such as 'voluntary', 'active' and 'passive' euthanasia, the section dealing with this topic is brief to the point of being misleading. However, such brevity is compensated for by an up-to-date bibliography for further reference and several pages of ethical codes which are useful to have in one volume. University of Manchester 